Berenbaum, 1967; Park et al., 1971; Han, 1972). This reactivity is, of course, immunologically non-specific, but an appreciable diminution in mitogen responsiveness seems likely to be indicative of a high degree of immune depression (Rubin, 1970). While it might be predicted that specific immune reactivity would be depressed as part of the general process, no evidence on this point is currently available.

We were unable to show significant inhibition of migration of the peripheral leucocytes of 24 patients with either malignant melanoma or breast carcinoma in the immediate postoperative period in the presence of the appropriate antigens. All patients who had been tested preoperatively $(20)$ had had striking reactivity to one or several tumour extracts immediately before operation. The minimum period of loss of reactivity was six days, and migration inhibition was restored in 17 out of 20 patients tested between six and 22 days.

The mechanism of the immunological depression is not known. Since the effect appeared to occur in all patients examined it could not be related to duration of operation, though anaesthetic agents do interfere reversibly with lymphocyte function (Nunn et al., 1970), and this is therefore a potentially relevant factor. Postoperative variations in adrenal cortical activity are well known, and the role of corticosteroids as proved immunosuppressive agents is worthy of consideration. Studies of the mechanism of this phenomenon are in progress. Regardless of its mechanism the deficiency of specific anti- tumour immune defence seems real and may well be relevant to the establishment of immediately aggressive metastases or slow growing latent metastases.

These preliminary observations clearly require confirmation and extension. If confirmed, the timing of operative procedures in cancer patients may require reappraisal. This seems especially the case with sequential procedures such as excision of a primary tumour followed after an interval of 10-14 days by removal of clinically involved nodes.

This study was conducted with the aid of the McMillan Research Funds of the University of Glasgow.

\section{References}

Andersen, V., Bjerrum, O., Bendixen, G., Schiødt, T., and Dissing, I (1970). International fournal of Cancer, 5, 367

Bendixen, G., and Søborg, M. (1969). Danish Medical Bulletin, 16, 1.

Cochran, A. J., Jehn, U. W., and Gothoskar, B. P. (1972). Lancet, 1, 1340. Ferraresi, R. W., Dedrick, C. T., Raffel, S., and Goihman-Yohr, M. (1969). fournal of Immunology, 102, 852.

George, N., and Vaughan, J. H. (1962). Proceedings of the Society for Experimental Biology and Medicine, 111, 514

Han, T. (1972). Lancet, 1, 742.

Madden, R. E., and Karpas, C. W. (1967). Archives of Surgery, 94, 307.

Nunn, J. F., Sharp, J. A., and Kimball, K. L. (1970). Nature, 226, 85.

Park, S. K., Brody, J. I., Wallace, H. A., and Blakemore, W. S. (1971). Lancet, $1,53$.

Riddle, P. R., and Berenbaum, M. C. (1967). Lancet, 1, 746

Rubin, A. D. (1970). In Proceedings of the Fifth Leukocyte Culture Conference, ed. J. E. Harris. London, Academic Press.

Wolberg, W. H. (1971). Cancer Research, 31, 798.

\title{
"Ischaemic" Colitis in Young Adults
}

\author{
A. W. CLARK, R. H. LLOYD-MOSTYN, M. R. DE C. SADLER
}

British Medical fournal, 1972, 4, 70-72

\section{Summary}

Four cases of transient haemorrhagic colitis seen in young adults resemble 10 others in the literature. The 14 cases are distinguished from the classical transient ischaemic colitis syndrome by their youth, the low incidence of stricture formation, and the prevalence of right-sided lesions.

\section{Introduction}

Since the first description of ulcerative colitis (Wilks and Moxon, 1875) two further types of colitis of unknown aetiology have been defined. Crohn's disease (Crohn, Ginzburg, and Oppenheimer, 1932) was soon shown to affect the colon as well (Colp, 1934) and could occur there in the absence of smallbowel lesions (Pugh, 1945). Analysis of cases described as segmental colitis (Crohn, Garlock, and Yarnis, 1947; Neuman, Bargen, and Judd, 1954) suggests that most showed the features of Crohn's disease. The third type of non-specific colitis has been labelled pseudomembranous or nectorizing (Pettet, Baggenstoss, Dearing, and Judd 1954). It should be distinguished from staphylococcal enteritis, which it closely resembles, and from ischaemic colitis (Goulston and McGovern, 1965).

King's College Hospital, London S.E.5

A. W. CLARK, F.R.C.S., Surgical Registrar

R. H. LLOYD-MOSTYN, M.R.C.P., Medical Registrar

M. R. DB C. SADLER, M.R.C.P., Medical Registrar
Ischaemic colitis was first described by Boley, Schwartz, Lash, and Sternhill (1963). Marston, Pheils, Thomas, and Morson (1966) classified the syndrome depending on the degree of ischaemia, which produced either infarction of the whole bowel wall or severe haemorrhagic colitis leading eventually to stricture formation or transient bloody diarrhoea with complete recovery. We report four cases of acute haemorrhagic colitis in young adults with complete resolution in three and progression to stricture in the fourth. The features are similar to those of 10 cases reported by others. The whole group differ appreciably from the classical ischaemic colitis syndrome in age and distribution of lesion. Furthermore the incidence of stricture formation appears to be very low.

\section{Case Reports}

Case 1.-A 21-year-old minicab driver had been investigated for transient attacks of abdonimal pain and vomiting, each lasting about one day. He had had six attacks in two years. No cause had been found. In May 1971 he was admitted to hospital with similar but more severe pain and vomiting. He had had diarrhoea since the onset of the pain and the stools contained a small amount of bright blood. On examination he was afebrile with upper abdominal tenderness. Sigmoidoscopy showed normal mucosa to $20 \mathrm{~cm}$. Barium-enema examination showed sawtooth irregularity (Fig. 1). Laparotomy showed oedematous thickening of the colon from the appendix to the upper part of the descending colon. The vessels appeared normal. The appendix was removed and showed a nonspecific chronic inflammatory infiltration. Postoperatively he recovered rapidly, and a further barium-enema film two months later showed the colon to have returned to normal. He remained symptom free.

Case 2.-A 26-year-old West Indian man was admitted to hospital in August 1971. He had been fit until the day before admission, when he developed colicky periumbilical pain. The pain soon became more generalized and severe, accompanied by 


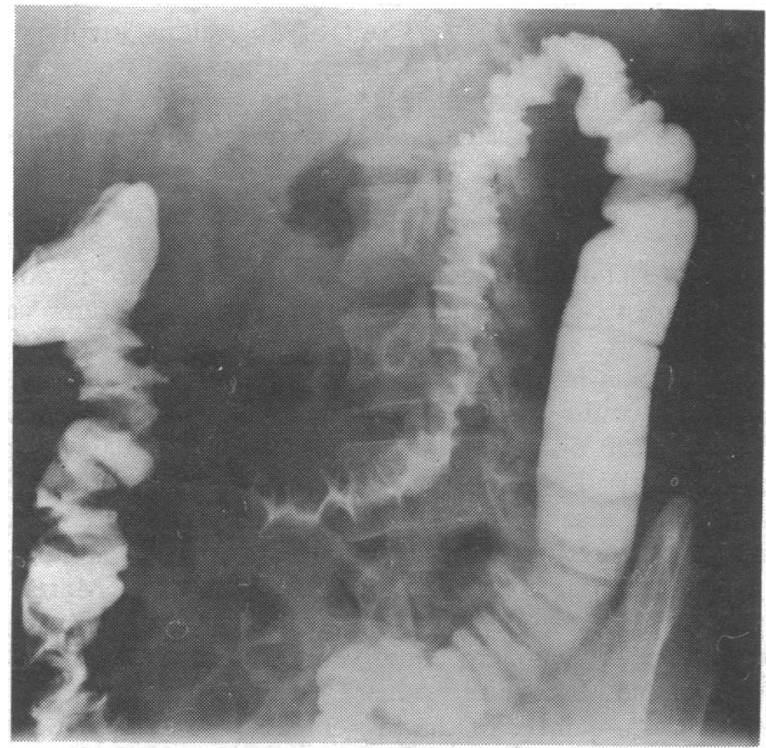

FIG. 1-Case 1. Barium-enema film showing sawtooth irregularity.

vomiting and bloody diarrhoea. On examination his temperature was normal and there was lower abdominal tenderness. Rectal examination showed copious heavily bloodstained liquid faeces. No mucosal lesion was seen on sigmoidoscopy to $26 \mathrm{~cm}$. After admission his pulse rate rose to $120 / \mathrm{min}$, and as his general condition was deteriorating a hydrocortisone drip was started. Investigations showed W.B.C. $13,000 / \mathrm{mm}^{3}$ ( $77 \%$ neutrophils), E.S.R. $23 \mathrm{~mm}$ in one hour, haemoglobin $16 \mathrm{~g} / 100 \mathrm{ml}$, and serum bilirubin $2.2 \mathrm{mg} / 100 \mathrm{ml}$. Blood cultures were sterile and no pathogens were grown from stool cultures. His condition improved on the day after admission and a barium-enema examination was performed. The colon could be visualized only as far as the hepatic flexure because he could not retain the enema. The transverse and descending colon was markedly irregular, with extensive "thumb-printing" (Fig. 2). The sigmoid colon and

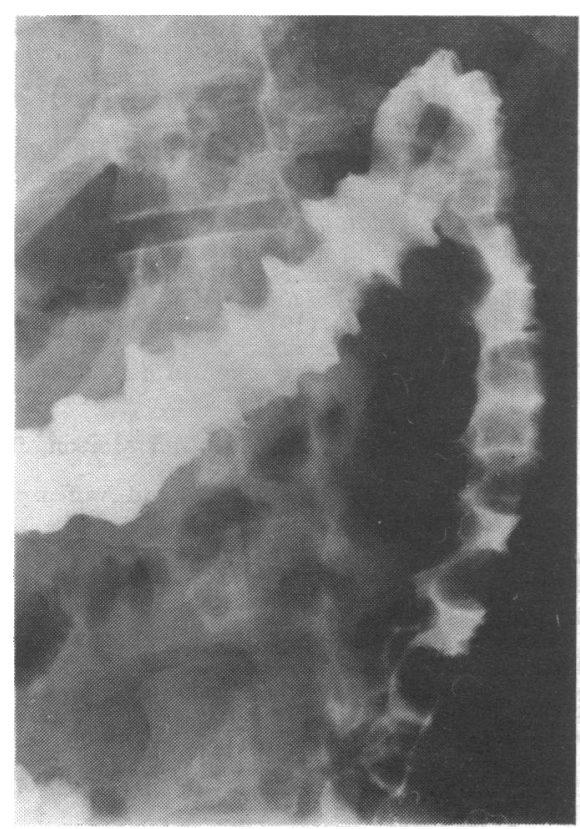

F1G. 2-Case 2. Barium-enema film showing irregular transverse and descending colon with extensive thumb-printing.

rectum were normal. Forty-eight hours after admission his symptoms had completely settled. A barium-meal examination was performed seven days after the onset of symptoms. The small bowel was normal and a follow-through film of the large bowel showed a normal mucosal pattern. He remained symptom free.
Case 3.-A 36-year-old housewife was known to be depressive and had been treated for some months with chlorpromazine, orphenadrine, and lithium carbonate. On the day before admission she had suddenly begun to have severe colicky abdominal pain radiating to the left loin. After two hours she started to have diarrhoea, and after 10 hours began to pass pure blood. She was admitted 30 hours after the onset of pain. Her temperature was $37.8^{\circ} \mathrm{C}$ and her pulse rate $120 / \mathrm{min}$. There was slight abdominal distension with tenderness and increased resistance in the left iliac fossa. Rectal examination showed fresh blood and clots. Sigmoidoscopy showed normal rectal mucosa. W.B.C. was $9,200 / \mathrm{mm}^{3}$, and haemoglobin $12.0 \mathrm{~g} / 100 \mathrm{ml}$. Because of the possibility of intussusception laparotomy was performed. This showed that the colon from just proximal to the splenic flexure to the mid-sigmoid was reddened, thickened, and narrowed with some exudate on its surface. A barium-enema examination on the third postoperative day showed narrowing and thumb-printing in the upper part of the descending colon (Fig. 3). By the fifth postoperative day her symptoms had subsided. Four months later a fibrous stricture with sacculation had formed (Fig. 4), although she remained symptom free.

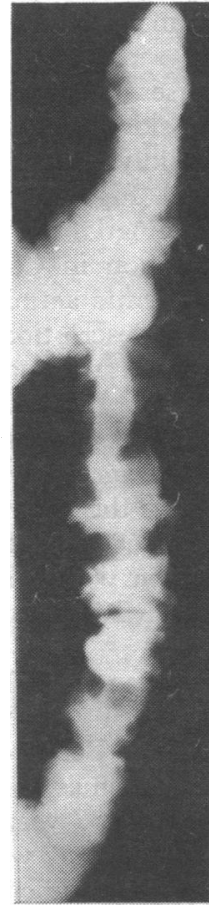

FIG. 3

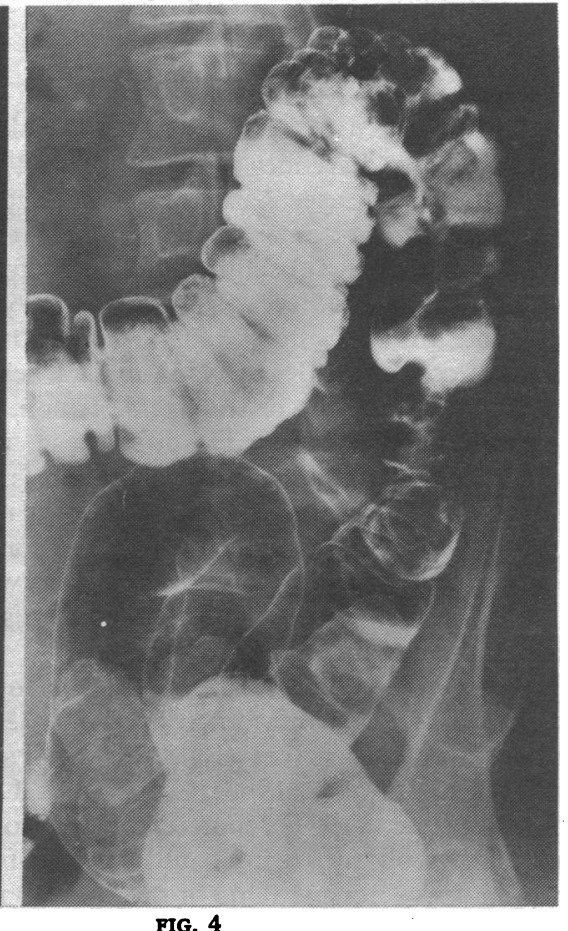

FIG. 4 FIG. 3-Case 3. Barium-enema film on third postoperative day showing narrowing and thumb-printing in upper part of descending colon. FIG. 4Case 3. Barium-enema film
stricture and sacculation.

Case 4.-A 22-year-old housewife presented in January 1971 when six months pregnant with her second child. The pregnancy had been uneventful and she had visited South Africa, returning two months before her illness. On the day of admission she developed severe colicky left-sided abdonimal pain and after eight hours began to pass bloody motions. Sigmoidoscopy showed normal mucosa to $15 \mathrm{~cm}$, which was confirmed by biopsy. The peripheral W.B.C. was $10,000 / \mathrm{mm}^{3}$ and stool cultures were negative. After 30 hours the pain increased and the left-sided tenderness became so severe that laparotomy was done. At operation the descending colon was thickened and inflamed from the splenic flexure to the lower third of the sigmoid colon. The blood supply appeared normal. Postoperatively her symptoms improved immediately. She delivered a normal baby at full term, and a subsequent bariumenema film showed nothing abnormal. She remained symptom free.

\section{Discussion}

These four cases will be discussed in relation to the possible diagnoses and then considered with cases described in the 
literature as ischaemic colitis but affecting patients under 42 years.

Crohn's Disease.-This disease can be excluded in the present patients on clinical grounds, for apart from the acute ileocaecal lesion usually included under this eponym there are no reports of complete resolution with subsequent normal barium-enema appearances. All the cases of acute segmental colitis in a large review from the Mayo clinic continued as chronic disease (Neuman et al., 1954).

Ulcerative Colitis.-Acute segmental ulcerative colitis is said to occur (de Dombal, Fletcher, and Harris, 1969), but the diagnosis is difficult to substantiate in the absence of rectal involvement (Watts, de Dombal, Watkinson, and Goligher, 1966a, 1966b).

Pseudomembranous Colitis. - This condition notably occurs in those with colonic obstruction or chronic renal or cardiac disease (Goulston and McGovern, 1965). In contrast, the present patients were healthy. Pseudomembranous colitis has been described in association with the barium-enema picture of thumb-printing. Pseudopolyposis was apparent, however, together with mucosal changes in the rectum (Jackson and Anders, 1972).

Ischaemic Colitis. - The clinical course in Cases 1, 3, and 4 is typical of "ischaemic colitis," with sudden left-sided abdominal pain and bloody diarrhoea which improved rapidly. The radiological features of Cases 2 and 3 were also typical (Figs. 2 and 3), while Case 4 did not have a barium-enema examination because of pregnancy. The subsequent stricture formation in Case 3 provides valuable indirect evidence of an ischaemic aetiology. Case 1 had a more watery diarrhoea than most descriptions of ischaemic colitis, and the radiological lesion is unusual in involving the right and transverse colon, although showing "sawtoothing" (Fig. 1). Despite these resemblances some factors weigh strongly against this diagnosis. The ages were not consistent with an atherosclerotic aetiology, unlike the age range of those with ischaemic colitis (Morson, 1968). Younger patients with ischaemic colitis tend to be women with cardiac disease, diabetes mellitus, or rheumatoid disease (Lea Thomas, 1968; Marcuson and Farman, 1971).

Similar Cases.-Three cases of "transient ischaemic colitis" have been described in women aged 29, 32, and 39 who were taking oral contraceptives (Kilpatrick, Silverman, Betancourt, Farman, and Lawson, 1968; Cotton and Lea Thomas, 1971). Dudley and Faris (1971) reported the syndrome in a 37-year-old woman in whom no drug could be incriminated and whose arteriogram was normal. One of the five original cases described (Boley et al., 1963) was of a fit young man aged 21. A similar condition in five young adults was labelled "evanescent colitis" (Miller, dePoto, Scholl, and Raffensperger, 1971). We are unable to include the cases reported by Marcuson and Farman (1972) as they were only briefly described. If these cases and the four described in this paper are considered together then three features distinguish them from the classical syndrome (Marston et al., 1966)-their youth, the low incidence of stricture formation, and the high frequency of right-sided lesions.

Age.-The age range in the series of Marston et al. was 44-82 years, and their youngest patient had atrial fibrillation. The range in the present four cases was 21-36 years and in all 14 cases 19-41 years. This is not consistent with an atherosclerotic aetiology (Morson, 1968).

Stricture Formation and Site.-In Marston's (1964) early series only one of the 14 cases resolved, the rest progressing to stricture; of the 14 cases reviewed here only one formed a stricture. Reviewing the original and subsequent cases, Lea Thomas (1968) stated that 33 out of 36 lesions involved the splenic flexure, and that two-thirds progressed to stricture. Nevertheless, only five of these 14 in the younger group had a lesion at this site. The remainder were in the right colon (eight cases), two of them having "skip lesions," and in the last case the lesion involved the transverse colon only.

Aetiology.-Apart from the clinical and radiological resemblance to the ischaemic lesions of older people there is no real evidence of a vascular aetiology in any of the younger cases. Indeed there are no descriptions of histological infarction or arterial occlusion in any cases of the transient type of ischaemic colitis. Nor could Marston reproduce this variety in dogs, possibly because of differences in intestinal vascular anatomy (Marston, 1964). Lea Thomas (1968) stated that arteriography continued to be disappointing in ischaemic colitis. More recently Marston has reproduced these lesions in dogs by venoligation, with all three main varieties of the syndrome (Marcuson, Stewart, and Marston, 1972). None of the present patients who had laparotomy had macroscopic venous thrombosis, nor were they so fat as to obscure the veins.

Management.-Three of the present cases underwent laparotomy, Case 1 because of previous negative investigation, and Cases 3 and 4 because they were thought possibly to have intussusception. Case 2 benefited from this experience. With awareness of the condition an emergency barium-enema examination would allow symptomatic treatment with an excellent prognosis.

We thank Sir Edward Grainger Muir, Mr. A. J. Heriot, Dr. S. G. Elkington, and Mr. H. E. Berry for permission to report details of cases under their care.

\section{References}

Boley, S. J., Schwartz, S., Lash, J., and Sternhill, V. (1963). Surgery, Gynecology and Obstetrics, 116, 53.

Cotton, P. B., and Lea Thomas, M. (1971). British Medical fournal, 3, 27. Colp, R. (1934). Surgical Clinics of North America, 14, 433

Crohn, B. B., Garlock, J. H., and Yarnis, H. (1947). Journal of the American Medical Association, 134, 324

Crohn, B. B., Ginzburg, L., and Oppenheimer, G. D. (1932). Fournal of the American Medical Association, 99, 1323.

de Dombal, F. T., Fletcher, D. M., and Harris, R. S. (1969). Gut, 10, 131 Dudley, H. A. F., and Faris, I. (1971). British Medical fournal, 3, 637.

Dudley, H. A. F., and Faris, I. (1971). British Medical fournal,

Goulston, S. J. M., and McGovern, V. J. (1965). Gut, 6, 207.

Jackson, B. T., and Anders, C. J. (1972). British fournal of Surgery, 59, 154. Ilpatrick, Z. M., Silverman, J. F., Betancourt, E., Farman, J.,
J. P. (1968). New England fournal of Medicine, 278, 438.

Lea Thomas, M. (1968). Proceedings of the Royal Society of Medicine, 61, 341.

Marcuson, R. W., and Farman, J. A. (1971). Proceedings of the Royal Society of Medicine, 64, 1080.

Marcuson, R. W., Stewart, J. O., and Marston, A. (1972). Gut, 13, 1.

Marston, A. (1964). Annals of the Royal College of Surgeons of England, 35, 151.

Marston, A., Pheils, M. T., Thomas, M. L., and Morson, B. C. (1966).

Gut, 7, 1. (1971). Radiology, 100, 71.

Morson, B. C. (1968). Postgraduate Medical fournal, 44, 665.

Morson, B. C. (1968). Postgraduate Medical fournal, 44, 665. Gynecology and Obstetrics, 99, 563 .
.

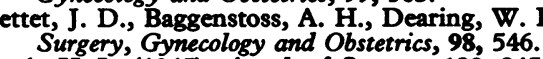

Pugh, H. L. (1945). Annals of Surgery, 132, 845.

Watts, J. McK., de Dombal, F. T., Watkinson, G., and Goligher, J. C. (1966a). Gut, 7, 16.

Watts, J. McK., de Dombal, F. T., Watkinson, G., and Goligher, J. C. (1966b). British Medical Yournal, 1, 1447.

Wilks, S., and Moxon, W. (1875). Lectures on Pathological Anatomy, 2nd edn. London, Churchill. 